\title{
ДИДАКТИЧЕСКИЕ ИГРЫ КАК СРЕДСТВО ФОРМИРОВАНИЯ ЛОГИЧЕСКИХ УНИВЕРСАЛЬНЫХ УЧЕБНЫХ ДЕЙСТВИЙ НА УРОКАХ МАТЕМАТИКИ В НАЧАЛЬНОЙ ШКОЛЕ
}

\section{Pихтер T.B., Антипина A.B.}

Федеральное государственное бюджетное образовательное учреждение высшего образования «Пермский государственный национальный исследовательский университет», г. Пермь,

Российская Федерация

В статье рассмотрена сущность логических универсальньх учебных действий, выделены в составе логические действия и мыслительные операции, выявлены виды дидактических игр, влияющие на их формирование при обучении математики детей младиего школьного возраста.

Ключевые слова: логические универсальные учебные действия; логические действия; мыслительные операџии; виды дидактических игр; математика; дети младшего школьного возраста.

\section{DIDACTIC GAMES AS A MEANS \\ FOR THE FORMATION OF LOGICAL UNIVERSAL EDUCATIONAL ACTIONS AT DOMAINS OF MATHEMATICS IN ELEMENTARY SCHOOL}

\section{Richter T.V., Antipina A.V.}

Perm National University, Perm, Russian Federation

The article examines the essence of logical universal educational actions, identifies logical actions and mental operations as part of it, identifies types of didactic games that influence their formation in teaching mathematics of children of primary school age.

Keywords: logical universal learning actions; logical actions; mental operations; types of didactic games; maths; children of primary school age. 


\section{Введение}

В соответствии с ФГОС начального общего образования один из метапредметных результатов освоения основной образовательной программы заключается в овладении такими логическими действиями, как сравнение, анализ, синтез, обобщение, классификация по родовидовому признаку, установление аналогии и причинно-следственной связи, построение рассуждения, отнесение к известному понятию, что указывает на необходимость формирования логических универсальных учебных действий (УУД) у детей младшего школьного возраста, влияющих на их познавательное развитие.

Вопросам выделения логических действий и мыслительных операций в составе логических УУД посвящены исследования А.Г. Асмолова, Л.И. Боженковой, Г.В. Бурменской, И.А.Володарской, 3.А. Дулатовой, А.И. Ковыршиной, Е.С. Лапшиной, А.В. Черепенниковой, Н.Н. Штыкова и др. Существуют различные подходы к формированию логических УУД: через расширение и углубление содержания дисциплин, изменение формата учебного занятия (Г.А. Аджемян, Н.Л. Будахина, В.А. Далингер и др.), исследовательскую деятельность (А.Г. Гейн, Е.М. Рекант и др.), реализацию деятельностного подхода (Д.И. Арсланалиева, Н.Г. Гашаров, Н.Г. Магомедов, Д.М. Нурмагомедов, Э.А. Рамазанова и др.), модульные и информационные технологии [1]. Одним из эффективных средств формирования логических УУД у детей младшего школьного возраста являются дидактические игры, реализующие принципы активного обучения и отличающиеся наличием правил, структуры игровой деятельности, системы оценивания. Вопросы использования дидактических игр рассмотрены в работах А.В. Артемовой, М.Н. Петровой, Д. Рао, А.А. Смоленцевой, Р. Стевенса и др. Маркушевская Е.А., Сиухина И.А. выделяют следующие функции дидактических игр: формирование устойчивых интересов к учению, психических новообразований и учебной деятельности, развитие общеучебных умений и навыков, самоконтроль и самооценка, адекватные взаимоотношения и освоение социальных ролей [2, с. 94]. 
В настоящее время особенно важно понимать значение математического развития детей, поэтому целесообразно использовать для формирования логических УУД дидактические игры с математическим содержанием.

Цель исследования: выявить виды дидактических игр, влияющие на формирование логических УУД у детей младшего школьного возраста на уроках математики. Гипотеза исследования: формирование логических УУД у детей младшего школьного возраста на уроках математики будет эффективным при использовании следующих видов дидактических игр на: сравнение по величине, количественные представления, расширение представлений о геометрических фигурах, временные представления, ориентировку в пространстве.

\section{Материалы и методы исследования}

Ведущими методами исследования явились обобщение и анализ научных трудов по теме исследования.

\section{Результаты исследования}

Выделены следующие логические действия и мыслительные операции в составе логических УУД: анализ объекта (выявление существенных и несущественных признаков); синтез объекта (составление целого из частей, самостоятельное достраивание и восполнение недостающих частей объекта); сравнение, сериация и классификация по родовидовому признаку (использование заданных критериев или их самостоятельный выбор); подведение под понятие (распознавание объектов, выделение существенных признаков и их синтез); установление аналогии и причинно-следственных связей; самостоятельное выдвижение гипотез и их обоснование; построение логической цепи рассуждений; осуществление доказательств собственных суждений; обобщение; выведение следствий; владение общими приёмами решения задач.

Анализ литературы по проблеме исследования позволил выделить виды дидактических игр, способствующие формированию логических УУД у детей младшего школьного возраста на уроках математики (таблица 1). 
Таблицуа 1.

Виды дидактических игр, способствующие формированию логических УУД

\begin{tabular}{|l|l|}
\hline Виды дидактических игр & Логические действия и мыслительные операции \\
\hline на сравнение по величине & $\begin{array}{l}\text { сравнение, сериация и классификация по родови- } \\
\text { довому признаку }\end{array}$ \\
\hline $\begin{array}{l}\text { на количественные пред- } \\
\text { ставления }\end{array}$ & анализ и синтез объекта, подведение под понятие \\
\hline $\begin{array}{l}\text { на расширение представ- } \\
\text { лений о геометрических } \\
\text { фигурах }\end{array}$ & $\begin{array}{l}\text { осуществление доказательств собственных сужде- } \\
\text { ний, обобщение, выведение следствий }\end{array}$ \\
\hline $\begin{array}{l}\text { на временные представ- } \\
\text { ления }\end{array}$ & $\begin{array}{l}\text { установление аналогии и причинно-следственных } \\
\text { связей, владение общими приёмами решения задач }\end{array}$ \\
\hline $\begin{array}{l}\text { на ориентировку в про- } \\
\text { странстве }\end{array}$ & $\begin{array}{l}\text { самостоятельное выдвижение гипотез и их обосно- } \\
\text { вание, построение логической цепи рассуждений }\end{array}$ \\
\hline
\end{tabular}

Анализ исследований В.Н. Аванесовой, А.К. Бондаренко, А.В. Соколовой, А.И. Сорокиной и др. позволил выделить следующие структурные компоненты дидактической игры: дидактические и игровые задачи; дидактический материал; игровые действия; игровые правила; результат. В качестве примера приведем конструкт дидактической игры с математическим содержанием «Поезд времени» для детей младшего школьного возраста (табл. 2).

Таблицуа 2.

\section{Конструкт дидактической игры «Поезд времени»}

Задачи: дидактическая - формирование умения выстраивать линию развития объекта в пределах его жизни и исторического развития; развитие связной речи, активизация в речи выражения «потом», «до», «после того как»

\begin{tabular}{|c|c|c|c|}
\hline Дидактический материал & $\begin{array}{l}\text { Игровые } \\
\text { действия }\end{array}$ & Игровые правила & Результат \\
\hline $\begin{array}{l}12 \text { вариантов изображения } \\
\text { одного объекта в разные } \\
\text { временные периоды (на- } \\
\text { пример: жизнь человека от } \\
\text { рождения и до старости) }\end{array}$ & $\begin{array}{l}\text { Детям раздаются } \\
\text { карточки, игра- } \\
\text { ющие выстра- } \\
\text { ивают «Поезд } \\
\text { времени» }\end{array}$ & $\begin{array}{l}\text { Вагончики выстраи- } \\
\text { вать в соответствии } \\
\text { с этапами развития } \\
\text { объекта, начиная с } \\
\text { его рождения }\end{array}$ & $\begin{array}{l}\text { «Поезд } \\
\text { време- } \\
\text { ни» по- } \\
\text { строен }\end{array}$ \\
\hline
\end{tabular}

Организация опытно-экспериментальной работы по проверке эффективности использования дидактических игр на уроках математики с целью формирования логических УУД включала 3 этапа (констатирующий, формирующий и контрольный) и проводилась с группами детей младшего школьного возраста в МАОУ СОШ № 17 
г. Соликамска (2 «А» - контрольный класс, 2 «Б»- экспериментальный класс) в количестве 50 обучающихся. Цель констатирующего этапа - выявление начального уровня сформированности логических УУД у детей младшего школьного возраста, контрольного этапа - анализ динамики показателей сформированности логических УУД. Использовался диагностический материал, разработанный на основе методики А.И. Алтунина «Тест на логические действия» и адаптированный для обучающихся начальной школы. Получены следующие результаты контрольного среза (рис. 1):

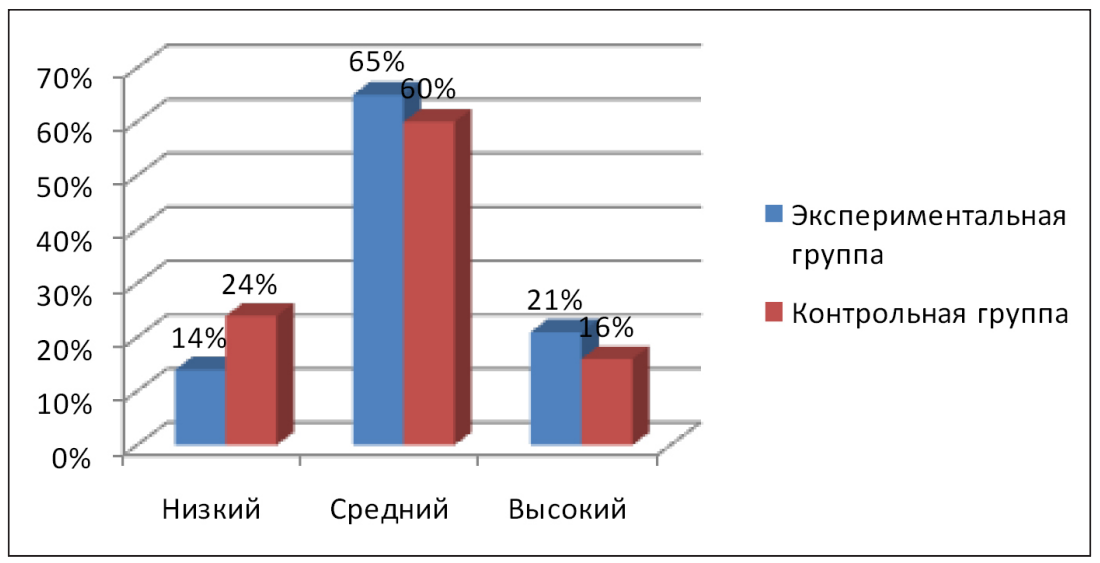

Рис. 1. Результаты контрольного среза

\section{Обсуждение}

Результаты контрольного среза показали, что в экспериментальной группе на 10\% меньше обучающихся с низким уровнем сформированности логических УУД, на 5\% больше со средним уровнем и на $5 \%$ больше детей с высоким уровнем. Исходя из количественной и качественной оценки полученных результатов, можно сделать вывод, что благодаря целенаправленной работе показатели сформированности логических УУД выше, чем на первоначальном этапе. Можно констатировать тот факт, что дидактическая игра способствует формированию у детей младшего школьного возраста на уроках математики логических УУД, т.е. гипотеза исследования подтвердилась 


\section{Заключение}

Дидактическая игра является многоплановым, сложным педагогическим явлением. Выделенные виды дидактических игр в курсе математики начальной школы будут способствовать формированию логических универсальных учебных действий и повышению качественного уровня образовательного процесса.

\section{Список литературы}

1. Рихтер Т.В. Реализация модульных и информационных технологий в условиях модернизации системы школьного математического образования // Инновации в образовании. 2007. № 8. С. 49-57.

2. Маркушевская Е.А., Сиухина И.А. Дидактическая игра как средство формирования логических универсальных учебных действий младших школьников // Проблемы и перспективы развития образования в России. 2016. № 38. С. 94-96.

\section{References}

1. Rikhter T.V. Realizatsiya modulnykh i informatsionnykh tekhnologiy v usloviyakh modernizatsii sistemy shkolnogo matematicheskogo obrazovaniya [Implementation of modular and information technologies in the context of modernization of the system of school mathematics education]. Innovatsii v obrazovanii, 2007, № 8, pp. 49-57.

2. Markushevskaya Ye.A., Siukhina I.A. Didakticheskaya igra kak sredstvo formirovaniya logicheskikh universalnykh uchebnykh deystviy mladshikh shkolnikov [Didactic game as a means of formation of logical universal educational actions of younger students]. Problemy i perspektivy razvitiya obrazovaniya v Rossii, 2016, № 38, pp. 94-96. 